\title{
How does business analytics contribute to organisational performance and business value? A resource-based view
}

\author{
Sheshadri Chatterjee \\ Department of Computer Science \& Engineering \\ Indian Institute of Technology Kharagpur \\ Kharagpur, West Bengal 721302, India \\ Email: sheshadri.academic@gmail.com \\ Nripendra P. Rana [Corresponding Author] \\ School of Management \\ University of Bradford \\ Richmond Road, Bradford, BD7 1DP, UK \\ Email: nrananp@gmail.com \\ Yogesh K. Dwivedi \\ Emerging Markets Research Centre (EMaRC) \\ School of Management \\ Swansea University Bay Campus \\ Fabian Way, Swansea, SA1 8EN, UK \\ Email: ykdwivedi@gmail.com
}

\begin{abstract}
Purpose - The purpose of this article is to identify how the organisations are able to improve their business value through acquisition of business analytics capabilities and by improving their performance.

Design/Methodology/Approach - With the help of literature survey, along with standard resource-based view framework, a conceptual model has been developed. These have been statistically tested by collecting the data using the survey questionnaire from 306 selected respondents from various service sector and product based organisations in India. To analyse the data we have used partial least square based structural equation modelling.

Findings - The study highlights that by the help of data acquisition and tool acquisition as two vital components, the acquisition of business analytics capabilities could improve the business value of the organisation by strengthening its organisational performance. The findings of this research also indicated that acquisition of business analytics capabilities has a significant influence on organisation's business process performance and business decision, which in turn significantly influence organisational performance. And, organisational performance eventually positively influences its business value. The model was found to provide an explanative power of $71 \%$.

Research Implication - The proposed research model can provide effective recommendations to the management of the organisations to realise the importance of acquisition of effective business analytics capabilities to eventually improve the business value of the organisation.

Originality/Value - No specific studies, as yet, have analysed the effects of acquisition of business analytics capabilities for improving organisational performance mediated through business process performance and business decision. Therefore, this research has explored the distinctive effort to empirically validate this understanding.

Keywords - Business Analytics, Business Value, Organisational Performance, Business Decision, Data Acquisition, Tool Acquisition
\end{abstract}

Paper Type - Research paper 


\section{Introduction}

Global business environment is changing rapidly (Cravens et al., 2009). Business organisations are found to depend more and more on modern technologies, which are experiencing unprecedented advancement. In this scenario, the organisations are bound to be more agile as well as innovative for swiftly responding to their business needs. To survive in this competitive ambiance, the organisations must have the ability to respond accurately and quickly to the sophisticated global marketplace needs. To achieve this, the organisations are to depend on data science with the help of developed information technology. These would require various tools and techniques to be acquired by the organisations to overcome the growing business challenges (Sharda et al., 2016). In this competitive environment, the organisations are needed to analyse huge volume of customers' data to identify their preference, likings, and dis-likings. Tackling huge volume of such data by the organisations through the offline traditional model is found to pose problems.

As such, organisations are now found to have depended on sophisticated analytics tools (Wang et al., 2016; Dahabiyeh et al., 2020). Availability of these datasets and use of sophisticated tools have made data science and information technology important for the organisations. This has helped the organisations to realise the business environment that would help the organisations to reach a meaningful business decision for their business growth (Sharma et al., 2014; Bichler et al., 2017). By acquisition of data through different means, the organisations would be able to arrive at a precise decision to improve their business value. The huge volume of data is statistically analysed and some decisions are taken based on that analysis and this may be referred to as business analytics (BA) (Delen et al., 2018; Zameer et al., 2020). The study collected data from 247 professionals from the USA (Schniederjans et al., 2016) for investigating the contributions of data 
collection and tool acquisition that could impact business analytics. This inference was also confirmed from another study conducted earlier based on 202 Korean organisations and it was found that data collection and tool acquisition played vital role to influence business analytics (Garrison et al., 2015).

Most of the growing organisations are reported to have invested huge amount to develop BA tools (Cosic et al., 2015; Oesterreich and Teuteberg, 2019; Sedera et al., 2019; Sha et al., 2020; Dahabiyeh et al., 2020). According to Accenture and General Electric, 89\% of the global organisations have started believing that they would incur loss if they do not adopt BA tools to reach correct business decision through improvement of their business processes (Columbus, 2014; Bakotic and Krnic, 2017; Uriona Maldonado, 2020). However, despite the popularity of the business analytics in the contemporary businesses, there is a controversy if an acquisition of BA capabilities would improve organisational performance and business value by enhancing business process performance through accurate real time business decision (Akter et al., 2016; Ramanathan et al., 2017). No studies are available how acquisition of business analytics capability could improve the organisational performance with real-time decision making (Loukis et al., 2019). This study aims to fill in this research gap by examining how the acquisition of business analytics capabilities improves business value of an organisation.

The remaining sections of the paper are structured as follows: Section 2 reviews the concerned literature. Section 3 presents the theoretical background and propose the conceptual model and hypotheses. Section 4 describes the research methodology with data collection strategy, research instruments and control variables. This is followed by data analysis and results in Section 5. Section 6 discusses the results in line with literature along with theoretical contributions, 
implications for practice and limitations and future research directions. Finally, Section 7 concludes the paper highlighting the key findings.

\section{Literature Review}

There are a number of studies on contribution of cloud computing for service providers of data (Iyer et al., 2012; Venters et al., 2012; Rodrigues et al., 2014; Uriona Maldonado, 2020) to the organisations but, not many of them have explored the role of business analytics towards the improvement of business value (Loukis et al., 2019; Sedera et al., 2019; Sha et al., 2020; Dahabiyeh et al., 2020). Malladi and Krishnan (2012) collected data from 243 US based organisations to study the impact of tool acquisition for successful implementation of BA solution and concluded that use of tool acquisition process has positive impact on the organisations' innovation in process, service and products. Garrison et al. (2015) also used survey data of 302 Korean organisations and concluded that data collection as well as proper tool selection have considerable impact in the process of business analytics. Institute of Operations Research and Management Science, of USA has suggested three progressive tiers of BA including descriptive, prescriptive, and predictive approach. In addition they also suggested that there are two main components of BA - data acquisition and tool selection (Delen et al., 2018; Oesterreich and Teuteberg, 2019). These components are considered most fundamental enabler ingredients of BA as observed from other studies (Wamba et al., 2017; Bakotic and Krnic, 2017, Zameer et al., 2020). Different studies have endeavored to study the impact of BA on organisational performance mediating through process performance and real time business decision (Klatt et al., 2011; Sharma et al., 2014; Troilo et al., 2016; Dennehy and Conboy, 2019; Tang and Chen, 2020). The study has emphasised the importance and effectiveness of the resources. The resources are used by the organisations for performing better. This concept is based on RBV framework. Studies reveal that 
acquisition of BA capabilities could enhance learning experiences and helps to revitalise the business and to gain adequate performance improvements (Wojcik, 2015; Ramanathan et al., 2017; Shehata et al., 2019; Siala et al., 2019; Chatterjee, 2020).

Other studies transpire that BA is associated with a wide range of applications and processes that include collection, storage and analysis of big data (Bayrak, 2015). BA involves utilisation of big data through qualitative and statistical techniques as has been found in other studies (Chae et al., 2014). Studies also highlight that BA helps to create a fact based management system (Holsapple et al., 2014; Bayrak, 2015). BA is interpreted as a set of technical and business activities with collection of processes and tools to move, manipulate and analyse business environment (Sun et al., 2017). Studies reveal that acquisition of BA capabilities can create business values and helps towards best usage of the resources (Hindle et al., 2018; Chatterjee et al., 2019). Schniederjans et al. (2016) used survey data collected from 247 ICT professionals from the USA for investigating how data collection as well as acquisition of tools could impact BA. The study concluded that data collection and acquisition of appropriate tools are associated with BA solution and these two are required to be considered as vital components of BA.

Studies have revealed that with development of organisational performance, the business value of the organisation is considerably improved (London, 2016; Jayashankar, 2019). Extant literature appears to have advocated how acquisition of BA capabilities could ensure success in the business of an organisation. However, there is a lack of research on how data as well as tool acquisition could impact BA. In other words, no studies have yet examined how acquisition of BA capabilities could influence business process and business decision for improving the organisation's performance, which in turn triggers its business value. 


\section{Theoretical Background, Proposed Conceptual Model and Hypotheses Development}

\subsection{Theoretical Background}

The proposed model is basically founded on the 'Resource Based View' (Kor and Mahoney, 2003), which is also known as 'Resource Advantage Theory' (Priem et al., 2001). It is a managerial

framework, which is used for determining the strategic resources necessary for an organisation to exploit for achieving sustainable competitive advantage to ensure business value. Under Resource Based View (RBV), the acquisition of BA application and impacts of BA on organisational performance through business process performance and business decision will be discussed. The $\mathrm{RBV}$ is structured surrounding the idea of developing abilities for utilisation of resources towards achievements for competitive advantage through improved organisational performance (Barney, 1991; Cosic et al., 2015; Gunasekharan et al., 2017; Delen et al., 2018).

It has been argued that success of an organisation lies on the fact how the organisation is collecting necessary resources and deploying the resources through its proper use (Peppard et al., 2016). It should be emphasised so that the resources are valuable, inimitable, rare as well as nonsubstitutable (VIRN) (Gunasekharan et al., 2017). In the perspective of BA acquisition, data should be construed to be one of the vital resources, which is needed to improve business operation. It has already been stated that data acquisition as well as tool acquisition have been considered as important indicators towards successful BA solution that would ensure competitive advantage for improvement of business value (Wamba et al., 2017).

Besides, quality data are needed to acquire an effective resource BA solution. This is considered as one ingredient for RBV to provide accuracy of data (Appelbaum et al., 2017). According to the RBV theory, the ability of an organisation to proactively create, extend and modify its resource base by the BA application would influence its promises to create conducive competitive 
advantage, which eventually increases business value (Vidgen et al., 2017). In terms of RBV, organisations need to acquire usable data which are valuable, inimitable, rare, and nonsubstitutable (Gunasekharan et al., 2017). These data are loaded to BA solution. The BA solution helps the organisations to adopt appropriate decision and to redefine the business process (Appelbaum et al., 2017). Accurate decision-making impacts performance of the organisations prompting business value. Data acquisition and tool acquisition can be considered as vital components of BA. It would help to extract data from various sources. Then the data are consolidated, summarised, and eventually loaded to BA solution (Sharda et al., 2016). This data acquisition based applications of information science may be considered to have been included as a part of BA acquisition in terms of RBV (Tan et al., 2016).

The RBV framework suggests that data acquisition and tool acquisition being vital components of BA help to design innovation while adopting appropriate resources along with appropriate argument (Hindle et al., 2018). This needs highly sophisticated mathematical modeling mechanisms to combat multi-objective situation for proposing appropriate recommendations to the top officials of the organisation as a special solution (Pape, 2015). Thus, it has been possible to elucidate how acquisition of correct data and selection of appropriate tools function as effective components of successful BA solution.

\subsection{Proposed Conceptual Model}

In terms of the above discussion, it is evident that the data and tool acquisition are vital components of BA and it impacts on organisational performance through business process performance along with ability to take real time business decision. Eventually, organisational performance affects business value of the organisation (Gunasekharan et al., 2017). Thus, the RBV framework has been able to explain how a successful acquisition of BA capabilities with its two main components 
i.e. data acquisition and tool acquisition influence organisational performance through effective business process of the organisation supported by accurate real-time business decision to eventually lead to improve business value. Based on the above discussion, Figure 1 illustrates the proposed conceptual model.

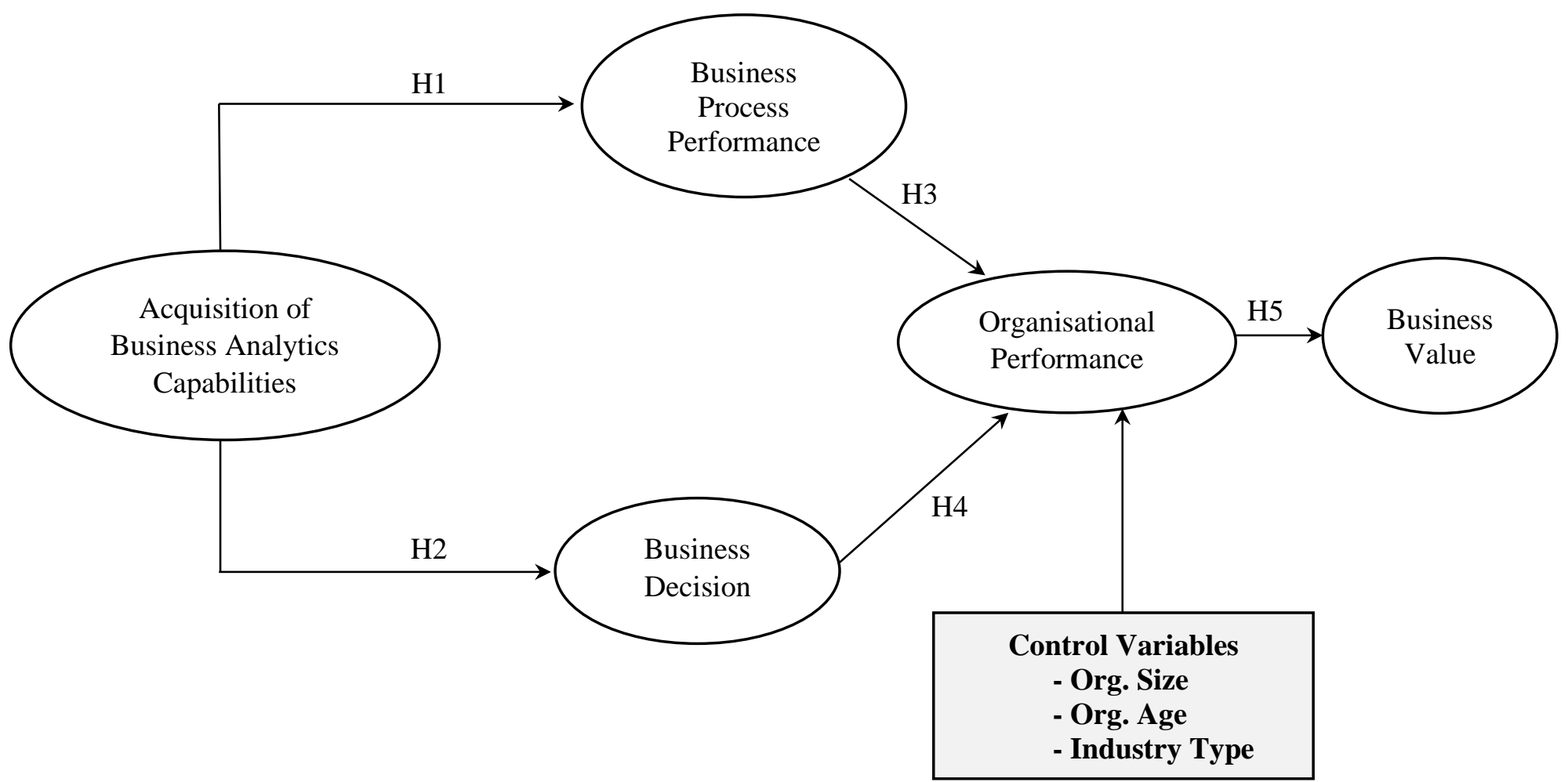

Figure 1: Proposed conceptual model (Source: adapted from Kor and Mahoney, 2003)

\subsection{Hypotheses Development}

\subsubsection{Acquisition of Business Analytics Capabilities (BA)}

Organisations would be able to achieve significant performance improvement if BA can be used in consonance with business process performance and following organisations' objectives (Ramanathan et al., 2017). Business process is a mechanism that can be conceptualised with complex and multi-disciplinary situations receiving various knowledge inputs from various resources. It is known that data can be considered as one of the vital components of BA and it helps to enhance effectiveness as well as business performance of the organisations through data exchange and information exchange (Sharma et al., 2014). Hence, acquisition of BA capabilities 
helps to provide appropriate solution to diagnose, support and improve the business process performance of the organisations (Sun et al., 2017).

It is known that data play a crucial role for the effective usage of BA solution in organisations (Cosic et al., 2015). It is possible to acquire data from different functional areas of the organisations. These include human resource, marketing, operations, finance and so on. It is important to note that the quality of data is important for the effective use of BA solution in organisation (Gunasekharan et al., 2017). In this context, the part played by the functional area lead is considered important in matters related with acquisition of data. It is to be borne in mind that legacy data is also important and effective relating to development of an effective BA solution in an organisation (Sharma et al., 2014).

The RBV theory advocates that the organisations must develop the abilities for appropriately utilising the resources to gain competitive advantage by improving their performance (Delen et al., 2018). Moreover, this theory also suggests that it is not only acquiring data but quality of data is equally important (Appelbaum et al., 2017). It is important to note that acquisition of data in real time situation helps for real time decision making, which is highly essential for accurate as well as appropriate BA solution of an organisation. Acquisition of data could be in multifarious forms (Bernhard et al., 2006). These include big data, external data of the organisation and internal data of the organisation. These data come from the various functional areas of the organisation. Hence, data acquisition is a vital component of any BA solution for an organisation.

It is observed that software is gradually becoming more and more sophisticated. In this perspective, selection of appropriate tools has become very important for ensuring successful BA solution for the organisation (Tan et al., 2016). It is the key responsibility of the leadership team to arrive at an appropriate decision whether to select on-premises tool or cloud-based solution (Bayrak, 2015). In 
consonance with RBV theory, appropriate tool acquisition is considered as one of the essential components of business analytics, which would help to extract data from different sources for their consolidation, summarisation, and finally loading to the different BA tools for visualisation (Sharda et al., 2016). Cost factor counts much in the selection of appropriate acquisition of BA capabilities. User experience is considered important in the tool selection process (Sun et al., 2017). In this context, a tool training is essential towards successful acquisition of BA capabilities in organisation (Mithas et al., 2011).

Many studies subscribe that BA provides a better value proposition for business, which eventually leads to business process performance (Bayrak, 2015). However, by altering business in organisation, applications of BA can bring in maximum influence for business value with improvement of business process (Cosic et al., 2015). Considering the above discussion, the following hypothesis is proposed:

H1: Acquisition of Business Analytics Capabilities (BA) positively influences Business Process Performance (BPP).

\subsubsection{Business Decision (BD)}

Any business organisation can take appropriate real-time business decision only if the organisation acquires appropriate BA solution aligning with the decision so arrived at along with the precise objective of the organisation (Appelbaum et al., 2017). The organisation should acquire BA solution, which can help in making appropriate business decision in such a way that it can be aligned with the overall objective of the organisation. Big data can also be considered as one of the vital ingredients of BA and by analysing big data, it would help the organisation to arrive at an precise business decision beneficial to the organisational performance (Chae et al., 2014; Pape, 2015). The organisations must have the abilities to acquire valuable, inimitable, rare, and non- 
substitutable (VIRN) data, which would be appropriate for the BA tools to analyse for reaching an accurate business decision. There are several studies to highlight that the acquisition of BA capabilities are perceived to have yielded better business value (Bayrak, 2015), but other related studies reveal that there is a direct impact of BA on decision making (Ramanathan et al., 2017). With all above discussion, the following hypothesis is proposed:

H2: Acquisition of Business Analytics Capabilities (BA) positively influences Business Decision (BD).

\subsubsection{Organisational performance $(O P)$}

Earlier studies indicate that there is a connection between the acquisition of BA capabilities and organisational performance in the context of increased competitive advantage that improves business value (Elbashir et al., 2008; Cosic et al., 2015). Studies also reveal that if investment is made for achieving successful BA solution, it would improve organisational performance (Laeson et al., 2016). In terms of RBV theory, it is evident that data is considered as an effective as well as strategic resource for an organisation to have appropriate BA solution by the process of acquiring VIRN data would eventually improve organisational performance. Studies show that there lies a link between acquisition of BA capabilities with business process performance (Troilo et al., 2017). It is also noted that acquisition of BA capabilities has influence on tangible and intangible performance of the organisations (Sun et al., 2017).

Studies show that acquisition of BA capabilities helps to achieve a collective and conducive business environment in a more practical way towards improvement of business value (Appelbaum et al., 2017). Application of optimum BA solution in an organisation renders the organisation to an evidence oriented problem solving organisation that clearly supports the performance of the organisation and the acquisition of BA capabilities also ensures better organisational performance 
for achieving competitive advantage improving its business value (Holsapple et al., 2014). It is believed that acquisition of BA capabilities can considerably improve the operational performance of the organisation (Klatt et al., 2011).

However, there are dearth of studies where there exists a linkage between the BA applications and organisational performance with inclusion of business process performance and business decision (Larson et al., 2016). In such circumstances, we posit that business process performance and business decisions serve as effective intermediating variables between acquisition of BA capabilities and organisational performance. With all the above discussion, the following hypotheses are followed:

H3: Business Process Performance (BPP) positively influences Organisational Performance $(O P)$.

H4: Business Decision (BD) positively influences Organisational Performance (OP).

\subsubsection{Business value $(B V)$}

The performance of the organisation is required to be harmonised with its objective (Bernhard et al., 2016). Performance of an organisation is associated with the conception of how the organisation has been able to carry out its operations that would lead to their success and business growth (Mithas et al., 2011). Operational excellence is considered as one of the vital indicators of performance of the organisation that can weigh its response to business needs and can access the productivity and sustainability for competition of the market (Wu et al., 2015). These all lead to improve business value of the organisation. Performance of an organisation also depends on the extent of investment, which enhances quality of the output (Brynjolfsson et al., 2000). Thus, the output quality is clearly related to the business value of the organisation. The performance of the organisation is assessed by its operational efficiency that eventually adds to the business value of 
the organisation (Elbashir et al., 2008). All these discussions lead us to propose the following hypothesis:

H5: Organisational Performance (OP) has a positive impact on Business Value (BV) of the organisation.

Earlier studies have suggested that some special characteristics of the organisation might impact some of the key constructs in connection with investigating the acquisition issues of BA in different organisations (Porter \& Donthu, 2006). Thus, for better and transparent delineation of the relations among the determinants in the proposed model, the authors here propose for inclusion of some variables characterising the organisational performance. These are organisational size, organisational age and industry type to provide an effective as well as rigorous analysis of the theoretical linkages.

\section{Research Methodology}

The hypotheses have been tested statistically using Partial Least Square (PLS) - Structural Equation Modelling (SEM) technique. This technique helps to relax rigorous process of normal distribution, which is not permitted in CB-SEM (Sarstedt et al., 2017). Moreover, PLS-SEM technique helps to analyse and assess a relatively complex model with no sample restriction (Lowry et al., 2014; Khan et al., 2019). PLS-SEM technique helps to yield effective results in exploratory studies (Willaby et al., 2015; Hair et al., 2018). We have used Smart PLS 3.2.3 for analysing data of this research.

\subsection{Measures}

With the help of studies of the extant literature, the items to measure the constructs have been used for ensuring content validity. However, through series of correctional procedures, they have been modified appropriately to fit the context of the instant study. Acquisition of Business Analytics 
Capabilities (BA) has been measured using six items in terms of knowledge taken mainly from Ramanathan et al. (2017); Sun et al. (2017); and Tan et al. (2016). Five measurement items have been framed relating to Business Process Performance (BPP) lending inputs from Bayrak (2015) and Sharma et al. (2014). Three measurement items have been articulated in connection with the construct Business Decision (BD) deriving knowledge from Pape (2015) and Appelbaum et al. (2017). Seven measurement items have been prepared relating to Organisational Performance (OP) with inputs from Bernhard et al. (2016); Mithas et al. (2011) and Wu et al. (2015). Four measurement items have been structured concerning the construct Business Value (BV) lending inputs from Brynjolfsson et al. (2000) and Elbashir et al. (2008).

To eliminate the defects of face validity and readabilities of the items, five experts in the field of the present study have been consulted. With their opinion, some minor rectifications have been made in the measurement instruments for improving their comprehensiveness. A pretest has been conducted for validation of these 25 measurement instruments and the instruments have been finally modified with the inputs from the pretest. In this way through step-by-step procedure as envisaged by Carpenter (2018) has been followed to finally prepare the instruments. The instruments have been prepared in the form of statements for having feedbacks for their quantification in 5-point Likert scale ranging from Strongly Disagree as ' 1 ' to Strongly Agree as ' 5 '. The details of the measurement instruments have been shown in Table 1.

Table 1: Measurement Instrument

\begin{tabular}{lll}
\hline Construct & Sources with Component & Measurement Items \\
\hline Acquisition of & Ramanathan et al., 2017; & BA1: I think data acquisition is most important for effective \\
Business & Sun et al., 2017; Tan et al., & business analytics solution for an organisation. \\
Analytics & 2016 & BA2: It is difficult to acquire data from different internal \\
Capabilities & & departments of the organisation for developing efficient \\
(BA) & & business analytics solution. \\
& BA3: Acquisition of external data is important for effective \\
& business analytics solution. \\
& BA4: Acquiring appropriate tool is important for effective \\
& & business analytics solution. \\
\hline
\end{tabular}






\subsection{Data Collection and Sample}

For selection of organisation of different sizes, age (year of operation) and different industry types, a list of different organisations has been taken from Mumbai Stock Exchange in India. Following the elimination process of the organisations, which were felt not to meet the selection criteria, a number of 150 organisations were randomly selected. Realistically, we sampled a wide range of 
organisations from various product-intensive industries with an expectation to get a high level of generalisability and external validity towards our research findings. The 150 firms were selected the list of large and medium sized organisations since most of the small organisations were reported not to apply BA tools for lack of resources. Initially, we tried to contact with the top officials of these 150 organisations but unfortunately most of them were found reluctant to cooperate with us. However, we could get hold of 15 organisations where the management (i.e. Senior Managers and Mid-level Managers) of those firms were agreed to provide response against the 25 questions. In total, we could contact 506 mangers at various positions for these organisations. They were requested through email to complete the questionnaire consisting of 25 questions. They were given enough time (i.e. from August 2019 to October 2019) to complete the survey. Within the stipulated time, we obtained 322 complete questionnaire with 16 incomplete responses. While intimating the respondents, we made them clear that the aim of this study was purely academic. They were also informed that their anonymity and confidentiality will be strictly preserved so that they could respond without any bias. They were instructed on how to fill in the response document. We did send them reminders to improve the response rate (Chidlow et al., 2015). As a result, we received an overall response of 306 usable responses with a response rate of $63.6 \%$. The demographic characteristics of respondents are presented in Table 2.

Table 2: Characteristics of the Sample

\begin{tabular}{llcc}
\hline Characteristics & Category & Number & Percentage (\%) \\
\hline Position of the respondent & Senior Manager & 192 & 62.7 \\
Organisational Size (Number of employees) & Mid-level Manager & 114 & 37.3 \\
& 501-2000 (Medium) & 102 & 33.3 \\
& Above 2000 (Large) & 204 & 66.7 \\
Organisation Age (Years of Operation) & Less than 3 years & 84 & 27.4 \\
& 3 to 10 years & 56 & 18.3 \\
& Above 10 years & 166 & 54.3 \\
Industry Type & Financial sector & 68 & 22.2 \\
& Telecommunication Sector & 56 & 18.3 \\
& IT Sector & 112 & 36.6 \\
& Healthcare Sector & 44 & 14.4 \\
& Retail Sector & 26 & 8.5 \\
\hline
\end{tabular}




\subsection{Control Variables}

The special characteristics of the organisation have been tested with the help of three control variables. First, organisational size has been measured with the help of number of employees in an ordinal form as shown in Table 2. Second, organisation age has been assessed by the number of years of operation from its very establishment. Third, for industry type, we have considered five sectors including financial sector, telecommunication sector, IT sector, healthcare sector and retail sector. Table 2 presents the overall split of these categories and the data gathered from each one of them.

\section{Data Analysis and Results}

The conceptual model consists of five constructs BA, BPP, BD, OP and BV. The constructs have been measured with 5-point Likert scale as already stated. This study also has considered some control variables characterising organisational performance.

\subsection{Data Analysis for Validity and Reliability}

To ascertain the convergent validity, the loading factor of each item has been measured. Composite Reliability (CR) as well as Average Variance Extracted (AVE) of each construct has been computed (Chin, 2010). For ensuring constructs' consistency, Cronbach's alpha $(\alpha)$ of each construct has been calculated. To test multicollinearity defect, Variance Inflation Factor (VIF) of each construct has been estimated. All the results are found to be within acceptable range (Hair et al., 2011; Kock and Lynn, 2012). The measurement properties are presented in Table 3.

Table 3: Measurement Properties

\begin{tabular}{lcccccc}
\hline Construct/Item & $\begin{array}{c}\text { Loading } \\
\text { Factor }\end{array}$ & t-value & $\begin{array}{c}\text { Cronbach's } \\
\text { alpha (a) }\end{array}$ & CR & AVE & VIF \\
\hline Acquisition of Business & $\begin{array}{c}\text { Analytics Capabilities (BA) } \\
\text { BA1 }\end{array}$ & 0.87 & 0.94 & 0.86 & 0.81 & 4.8 \\
BA2 & 0.90 & 21.47 & & & & \\
BA3 & 0.95 & 19.57 & & & & \\
BA4 & 0.90 & 28.41 & & & & \\
BA5 & 0.88 & 26.21 & & & & \\
BA6 & 0.89 & 24.71 & & & & \\
\hline
\end{tabular}




\begin{tabular}{|c|c|c|c|c|c|c|}
\hline \multicolumn{3}{|c|}{ Business Process Performance (BPP) } & \multirow[t]{6}{*}{0.96} & \multirow[t]{6}{*}{0.89} & \multirow[t]{6}{*}{0.86} & \multirow[t]{6}{*}{4.7} \\
\hline BPP1 & 0.93 & 28.11 & & & & \\
\hline BPP2 & 0.95 & 23.10 & & & & \\
\hline ВРP3 & 0.90 & 27.88 & & & & \\
\hline BPP4 & 0.94 & 24.17 & & & & \\
\hline BPP5 & 0.91 & 22.24 & & & & \\
\hline \multicolumn{3}{|c|}{ Business Decision (BD) } & \multirow[t]{4}{*}{0.93} & \multirow[t]{4}{*}{0.91} & \multirow[t]{4}{*}{0.85} & \multirow[t]{4}{*}{3.9} \\
\hline BD1 & 0.92 & 22.18 & & & & \\
\hline BD2 & 0.90 & 26.72 & & & & \\
\hline BD3 & 0.95 & 24.88 & & & & \\
\hline \multicolumn{3}{|c|}{ Organisational Performance (OP) } & \multirow[t]{8}{*}{0.95} & \multirow[t]{8}{*}{0.92} & \multirow[t]{8}{*}{0.88} & \multirow[t]{8}{*}{3.7} \\
\hline OP1 & 0.91 & 22.12 & & & & \\
\hline OP2 & 0.97 & 29.37 & & & & \\
\hline OP3 & 0.95 & 22.46 & & & & \\
\hline OP4 & 0.90 & 19.48 & & & & \\
\hline OP5 & 0.90 & 26.88 & & & & \\
\hline OP6 & 0.95 & 25.27 & & & & \\
\hline OP7 & 0.98 & 27.11 & & & & \\
\hline \multicolumn{3}{|c|}{ Business Value (BV) } & \multirow[t]{5}{*}{0.89} & \multirow[t]{5}{*}{0.88} & \multirow[t]{5}{*}{0.84} & \multirow[t]{5}{*}{4.1} \\
\hline BV1 & 0.93 & 26.42 & & & & \\
\hline BV2 & 0.88 & 27.11 & & & & \\
\hline BV3 & 0.89 & 28.95 & & & & \\
\hline BV4 & 0.96 & 21.17 & & & & \\
\hline
\end{tabular}

\subsection{Discriminant Validity Test}

For confirming the discriminant validity, square root of each AVE was estimated. The square root of each AVE is found to be greater than the corresponding correlation coefficients of that construct with other constructs. It confirms discriminant validity (Forenell and Larcker, 1981). The results are presented in Table 4.

Table 4: Discriminant Validity Test

\begin{tabular}{lccccccccc}
\hline $\begin{array}{l}\text { Construct/Con } \\
\text { trol variable }\end{array}$ & $\begin{array}{c}\text { Org. } \\
\text { Size }\end{array}$ & Org. Age & $\begin{array}{c}\text { Ind. } \\
\text { Type }\end{array}$ & BA & BPP & BD & OP & BV & AVE \\
\hline Org. Size & 1.00 & & & & & & & & 1.00 \\
Org. Age & 0.06 & 1.00 & & & & & & & 1.00 \\
Ind. Type & 0.46 & $0.40^{*}$ & 1.00 & & & & & & 1.00 \\
BA & 0.28 & $0.05^{*}$ & 0.40 & 0.90 & & & & & 0.81 \\
BPP & 0.13 & -0.07 & $0.38^{*}$ & 0.40 & 0.93 & & & & 0.86 \\
BD & $0.24^{*}$ & $0.11^{* *}$ & 0.06 & 0.31 & 0.22 & 0.92 & & & 0.85 \\
OP & -0.40 & 0.23 & $-0.41^{* *}$ & 0.37 & $0.38^{* *}$ & 0.26 & 0.94 & & 0.88 \\
BV & 0.36 & 0.31 & -0.38 & 0.21 & 0.07 & $0.21^{* * *}$ & $0.12^{*}$ & 0.92 & 0.84 \\
SD & -- & -- & -- & 1.17 & 1.16 & 1.11 & 1.02 & 1.09 & -- \\
Mean & -- & -- & -- & 3.46 & 5.11 & 4.12 & 4.66 & 3.71 & -- \\
\hline
\end{tabular}

To supplement the Fornell and Larcker criteria, we have also conducted Heterotrait-Monotrait (HTMT) correlation ratio test as recommended by Henseler et al. (2014). The results in this test 
show that all the concerned values of the constructs are less than 0.85 (Voorhees et al., 2016). It also confirms discriminant validity. The results are presented in Table 4a.

Table 4a: Discriminant Validity Test (HTMT criteria)

\begin{tabular}{lccccc}
\hline Construct & BA & BPP & BD & OP & BV \\
\hline BA & - & & & & \\
BPP & 0.34 & - & & & \\
BD & 0.32 & 0.26 & - & - & - \\
OP & 0.19 & 0.29 & 0.33 & 0.25 & \\
BV & 0.27 & 0.41 & 0.38 & 0.25 \\
\hline
\end{tabular}

\subsection{Common Method Variance (CMV)}

Since the study stands on the foundation of self-reported data, CMV is required to be performed. However, as a preemptive measure, at the time of survey, all the prospective respondents were assured that their identity will not be disclosed. However, for verifying if there is still any bias in the data, Harman's SFT (Single Factor Test) has been performed that transpired that the first factor emerged with $39.06 \%$ which is less than the highest cutoff value of 50\% (Podsakoff et al., 2003). Hence the data could not distort the results.

\subsection{Hypothesis Testing}

Bootstrapping procedure with Smart PLS has been used for hypothesis testing. This process helps us to test the hypotheses without conducting parametric test (Chin, 2010). In the PLS-SEM approach bootstrapping procedure is always recommended. In this approach we have used 5000 resamples with 306 cases (Henseler et al., 2009). This approach has helped us to find out path weights of different linkages, p-values and coefficient of determinants $\left(\mathrm{R}^{2}\right)$ values. The entire results are shown in Table 5.

Table 5: Results of Hypothesis Testing with p-values and $\mathrm{R}^{2}$

\begin{tabular}{lllll}
\hline Path & Hypothesis & Path-weight// & p-value & Remark \\
\hline Effect on BPP & & $\mathrm{R}^{2}=0.48$ & & \\
by BA & $\mathrm{H} 1$ & 0.46 & $* * \mathrm{p}<0.01$ & Supported \\
$\begin{array}{l}\text { Effect on BD } \\
\text { by BA }\end{array}$ & $\mathrm{H} 2$ & $\mathrm{R}^{2}=0.39$ & & \\
Effect on OP & & 0.31 & $* \mathrm{p}<0.05$ & Supported \\
by BPP & $\mathrm{H} 3$ & $\mathrm{R}^{2}=0.52$ & & \\
by BD & $\mathrm{H} 4$ & 0.44 & $* * \mathrm{p}<0.01$ & Supported \\
\hline
\end{tabular}




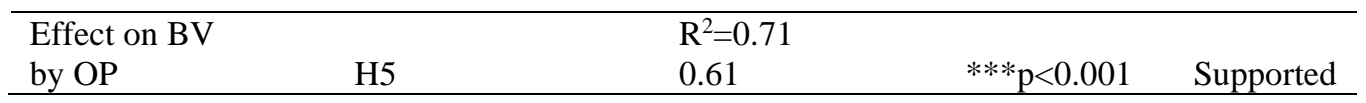

A Sobel test (Baron and Kenny, 1986) has been conducted. It appears that, so far as control variables are concerned, age and industry type of organisations were found insignificant to impact organisational performance. Only size has been found to possess positive as well as significant standardised coefficient on organisational performance $(\mathrm{p}<0.05)$. This signifies that organisations of large size show higher performance. After the PLS-SEM statistical analysis, it has been possible to validate the conceptual model by estimating the path coefficients, $\mathrm{R}^{2}$ value and $\mathrm{p}$-value. The entire results are shown through the Figure 2.

\subsection{Results}

From the understanding of the existing theories and the review of literature, it has been possible for us to propose a research model and formulate five hypotheses such as $\mathrm{H} 1(\mathrm{BA} \rightarrow \mathrm{BPP}), \mathrm{H} 2$ $(\mathrm{BA} \rightarrow \mathrm{BD}), \mathrm{H} 3(\mathrm{BPP} \rightarrow \mathrm{OP}), \mathrm{H} 4(\mathrm{BD} \rightarrow \mathrm{OP})$ and $\mathrm{H} 5(\mathrm{OP} \rightarrow \mathrm{BV})$. All these five hypotheses have been supported. Effect of BA on BPP is appreciable because the corresponding linkage bears the path weight 0.46 with appreciable level of significance $(* *, \mathrm{p}<0.01)$. This has supported H1. Besides, the path coefficient of linkage arising out of $\mathrm{H} 2(\mathrm{BA} \rightarrow \mathrm{BD})$ is seen to be also not less and it is 0.31 with level of significance $(*, p<0.05)$ supporting $\mathrm{H} 2$. The path coefficient bridging the linkage arising out of $\mathrm{H} 3(\mathrm{BPP} \rightarrow \mathrm{OP})$ is 0.44 with level of significance $(* *, \mathrm{p}<0.01)$, which supports $\mathrm{H} 3$. 


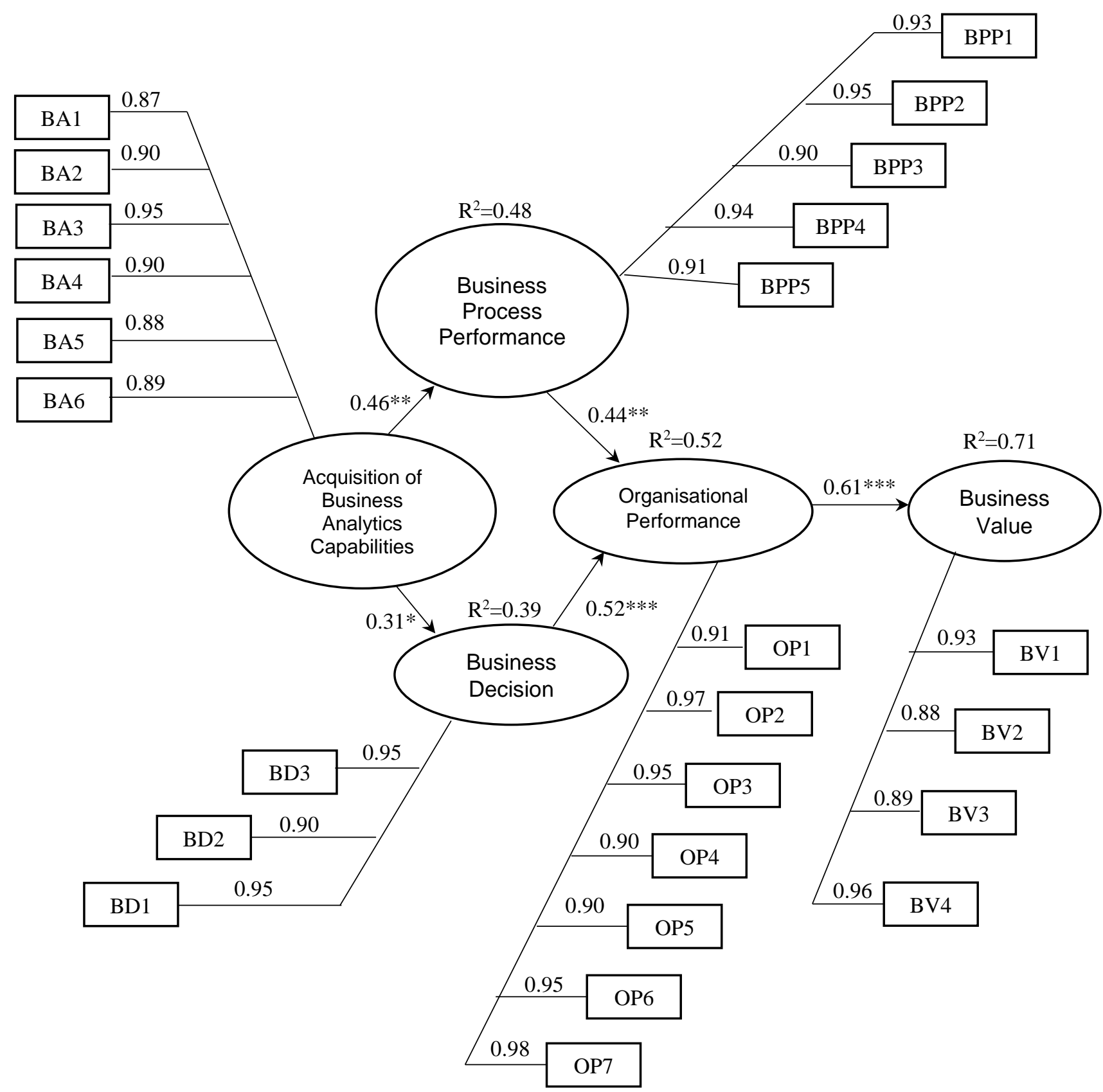

[Note: *: p<0.05; **: $\mathrm{p}<0.01$ and $* * *: p<0.001]$

Figure 2: Validated research model with measurement instruments

The path coefficient concerning to $\mathrm{H} 4$ linkage $(\mathrm{BD} \rightarrow \mathrm{OP}$ ) appears to be 0.52 with appreciable level of significance (***, p<0.001) supporting H4. Out of these two linkages covering hypotheses H3 and $\mathrm{H} 4$, the effect on OP by BD is more compared to the effect on OP by BPP as it appears from 
the magnitude of the corresponding path coefficient. The impact of OP on BV (H5) is also appreciable since the corresponding path coefficient appears to be as high as 0.61 with level of significance $(* *, p<0.01)$. Now, the different values of coefficient of determinant provide us a clear picture regarding the explanative effect. It appears that BPP could be explained by BA to the extent of $48 \%$ since corresponding $\mathrm{R}^{2}=0.48$. Again, $\mathrm{BA}$ has been able to explain $\mathrm{BD}$ to the tune of $39 \%$ since the related $\mathrm{R}^{2}=0.39$. The impact of both $\mathrm{BPP}$ and $\mathrm{BD}$ on $\mathrm{OP}$ highlights that these two endogenous variables could explain $\mathrm{OP}$ to the tune of $52 \%$ as the corresponding $\mathrm{R}^{2}=0.52$. The results of the validation show that the BV could be interpreted by OP to the tune of $71 \%$ since the corresponding coefficient of determinant is 0.71 . The model possesses high explanative power of $71 \%$.

\section{Discussion}

The study highlights that business analytics comprises of two components i.e. data acquisition and tool acquisition. The model after statistical validation transpires that acquisition of business analytics capabilities could impact both on business process performance as well as on business decision confirming the hypotheses $\mathrm{H} 1$ and $\mathrm{H} 2$. This result has received support from earlier studies (e.g. Sharma et al., 2014; Sun et al., 2017; Appelbaum et al., 2017; Pape, 2015). The existing studies have supplemented that use of BA tools in any type of organisation has effective impact on the process performance of the organisation and also BA capabilities have effective impact to influence the business decision of the organisations, which are considered vital for business activities of the organisations. It has transpired that acquisition of BA capabilities are expensive and as a result of that in our survey while attempting to statistically validate the model, we did not find any small organisations to use BA solution due to its resource constraint. 
Again, business process performance has been considered as a good predictor of organisational performance as is seen from the statistical approach confirming Hypothesis H3. This result has been supplemented by earlier studies (e.g. Larson et al., 2016), which hypothesised that if the process of business runs in a better way in an organisation, it impacts the overall performance of the organisation. This study also shows that the business decision has an effective contribution on organisational performance confirming Hypothesis $\mathrm{H} 4$, which is in consonance with the results of other earlier studies (Troilo et al., 2017; Appelbaum et al., 2017) where it has been seen that if an organisation fails to take appropriate decision, especially, in the context of demand and needs of the customer, the overall performance of the organisation is hampered.

This study has shown that strong business performance of the organisation has contributed to the business value of the organisation supporting Hypothesis H5, which has received support from earlier other studies (e.g. Elbashir et al., 2008; Wu et al., 2015) where it has been seen that accurate and flawless performance of an organisation can bring in appreciable business benefits enhancing their business value. Thus, acquisition of BA capabilities could improve the organisational performance through improvement of process performance and business decision and once organisational performance is improved, it will help to develop business value.

The approach of this study has emphasised on acquisition of accurate and usable data. This is complemented by RBV theory. The study has highlighted contributions of business analytics for improving business value (Rodrigues et al., 2014). BA contains three progressive tiers including descriptive, prescriptive, and predictive. This study has shown that the BA enhances learning experience helping to understand the business to accomplish better performance (Ramanathan et al., 2017). This study has highlighted that BA solution is associated with a wide range of applications including appropriate data analysis, which help the organisations to take the 
appropriate process to proceed and to take accurate decision thereby improving the organisational performance (Chae et al., 2014; Pape, 2015).

\subsection{Theoretical Contributions}

This study sets out to further the existing research on business analytics to offer more comprehensive and informed narrative on acquisition of BA capabilities and its impact on business value. In developing the proposed model, Resource Based View framework has been used which is considered as an effective managerial framework for determining the strategic resources, which organisations can exploit for achieving sustainable business value. The study has theorised by synthesising different components of business analytics tool for improving the organisational performance mediating through endogenous factors such as process performance and business decision. Use of these two mediating variables has strengthened the viability and effectiveness of the model and consequently helped it to achieve the high explanative power of $71 \%$.

Moreover, consideration of three control variables characterising the organisational performance has enriched the model further as one control variables (size) has strengthened the effect of organisational performance. As this research is fundamentally concerned with the acquisition of business analytics with the study of its consequential eventualities, some more relevant constructs have been used to achieve the high explanative power. The proposed research model could be considered as a parsimonious model triggering organisational performance for deriving improved business value of an organisation. There are various studies where organisational performance has been shown to be influenced by acquisition of business analytics capabilities.

However, none of these studies are based on the research model where the influence of acquisition of BA capabilities on organisational performance has been shown to strengthen through intermediating variables such as business process performance and business decision. Use of these 
intermediating variables seems to improve organisational performance. The proposed research model is expected to bring in a changed concept of the business players of organisations by developing their ideas about moderating scenario as traditionally the target of organisations remains confined to make profits by improving the quality of products and to reduce product cost. This is perhaps the first research that has highlighted the urgent need of business analytics tools to enhance performance of the organisations through developed process and by accurate decision making that would eventually improve the business value.

This study has provided inputs to the researchers to study how performance of organisations can be improved for increasing business value through appropriate acquisition of business analytics tools. Existing studies (e.g., Delen et al., 2003; Sharda et al., 2014) have proposed several dimensions such as domain (refers to fields and areas in which analytics is employed), method (highlights the approaches used to analyse the data) and orientation (refers to the line of thought and is not distinctive to one or the other business domain) for business analytics. However, in this study we have used two most important dimensions of BA, which are data acquisition and tool acquisition and by such consideration, the theoretical model could achieve high explanative power. This study has highlighted that there is a direct linkage between BA and business process performance that highlights that BA solution can be considered to have been integrated with process of the organisation (Tan et al., 2016). Moreover, none of the existing studies have proposed the impact of BA on organisational performance using intermediating variables such as business process performance and business decision. This study is claimed to have enriched the body of literature in this respect as well. 


\subsection{Managerial Implications}

The study has been able to project various implications for the managers of the organisations to improve their business value. Studies have revealed that BA solution would eventually impact organisational performance that would improve business value of an organisation. But in this

study, it has been noted that for paucity of funds, the small organisations are not being able to acquire BA solution across their organisations. The managers of small organisations are needed to convince the top management of the organisation for arranging of financial support so that acquisition of BA capabilities can be ensured in those small organisations for improving business value. It is observed that there is a direct linkage between acquisition of BA capabilities and improvement of business process performance. Now this implies that by improving the process and by real-time business decision, the performance of the organisation can be improved to ensure business growth.

As such the managers of the organisations should be vigilant so that the business processes can be improved and the managers should also focus attention on the points that the organisation does not fail to take real time accurate decision. Now decision-making mechanisms are considered as a joint effort when every employee of an organisation will have some contributions in decision making. Such being the situation, the managers of the organisations should arrange to train every employee properly so that each employee can take part in the decision-making process. This will enhance the performance of the organisation to increase business value. In the initial level, the organisational authorities are needed to use the appropriate business tools to analyse the data and for this, the concerned authorities selecting to acquire appropriate tools must be well conversant in this context. 
The role of managers in this respect is perceived to be very crucial. In the complex and dynamic business environment, application of BA with the help of inimitable data would help the authorities of the organisations to realise the business dynamics better. The managers need to verify the market assumptions with real data by the help of BA solution to enhance business value of the organisations. The managers must be serious to see that managerial decision-making in all level of the organisation must be carried out basing on the ground reality (Klett et al., 2011). The managers are to be sincere to confirm that there must be optimisation of business operations, there should be a proper forecasting of the outcomes, appropriate decisions and attempts need to be made for innovating new products and new services. If these are ensured by the use of BA solution, the organisations would be able to improve overall performance that would help to increase their business value.

\subsection{Limitations and Future Research Directions}

Like any other studies, this study also has some limitations. First, we did not consider the commitment of the top management concerning the culture of the organisation towards BA acqusition. This may be considered as a moderating variable in the future research. For investigating organisational performance, we have used three control variables including organisation size, organisation age, and industry type. But there are other variables like R\&D factor, revenue issue, etc., which may also control the performance of the organisations. These control variables could be considered as a part of future research. Second, while validating the research model using relevant data, the survey was conducted in India and the results obtained may be country specific. Hence, the findings of this research may lack generalisability. Therefore the findings of this research need to be applied in the other context with a certain level of caution. The future research could also consider collecting data from the developed economy to test the 
proposed model. Third, the sample size of the survey is not large enough. Hence, the future researchers could plan to collect a larger sample to validate the proposed research model. Third, we have used RBV framework to interpret an acquisition of BA capabilities and its linkage with performance. There are other alternative ways to study the relationships of some of these key constructs through a variety of other theoretical lenses like stakeholder theory, institutional theory, etc. Again, in the countries like India, the complete BA solution in organisations are yet to be experienced, hence the survey responses may be obtained from non-users of BA solution. Therefore, the proposed model could be applied in the mature environment where complete BA solution has already taken place, or other boundary conditions might be included to improve the model. The future researchers might take appropriate initiatives to cultivate some of these unearthed points.

\section{Conclusion}

The study has been able to establish the viability and importance of business analytics for the improvement of organisational performance. It has been noted in the study that acquisition of business analytics in an organisation helps to improve overall business performance of the organisation that in turn influences the organisational performance positively eventually improving the business value of the organisation. It has been also observed that acquisition of business analytics capabilities help the organisation to take appropriate business decision at the right time that can help to improve organisational performance providing better business value. It is a fact that organisational performance is improved significantly by the acquisition of business analytics in the organisation, but it depends on the size of the organisation. This control variable (size) considerably impacts organisational performance in selecting various business analytics solution. Finally, as it is seen that performance of an organisation is improved by the acquisition 
of appropriate business analyticscapabilities, it also provides better business growth to the organisations by improving the business process and real time decision making.

Acknowledgement: We declare that we do not have any potential conflict of interest in this research nor we have taken any further support from a third party for completing this entire research work.

\section{References}

Akter, S., Wamba, S. F., Gunasekaran, A., Dubey, R., and Childe, S. J. (2016), "How to improve firm performance using big data analytics capability and business strategy alignment?" International Journal of Production Economics, Vol. 182, pp. 113-131.

Appelbaum, D., Kogan, A., Vasarhelyi, M., and Yan, Z. (2017), "Impact of business analytics and enterprise systems on managerial accounting", International Journal of Accounting Information Systems, Vol. 25, pp. 29-44.

Bakotic, D. and Krnic, A. (2017), "Exploring the relationship between business process improvement and employees' behavior", Journal of Organizational Change Management, Vol. 30 No. 7, pp. 1044-1062.

Barney, J.B. (1991), "Firm resources and sustained competitive advantage", Journal of Management, Vol. 17 No. 1, pp. 99-120.

Baron, R. M., and Kenny, D. A. (1986), "The moderator-mediator variable distinction in social psychological research: Conceptual, strategic, and statistical considerations", Journal of Personality and Social Psychology, Vol.51 No.6, pp.1173-1182.

Bayrak, T. (2015), "A review of business analytics: A business enabler or another passing fad", Procedia-Social and Behavioral Sciences, Vol. 195, pp. 230-239.

Bernhard, W., Peter, B., Zoltan, M. P., and Maria-Luise, O. (2006), "The impact of ERP systems on firm and business process performance", Journal of Enterprise Information Management, Vol. 19 No. 1, pp. 13-29.

Bichler, M., Heinzl, A., and Van der Aalst, W.M.P. (2017), "Business analytics and data science: Once again?” Business \& Information Systems Engineering, Vol. 59 No. 2, pp. 77-79.

Brynjolfsson, E., and Hitt, L. M. (2000), "Beyond computation: Information organizational transformation and business performance", The Journal of Economic Perspectives, Vol. 14 No. 4, pp. 23-48.

Carpenter, S. (2018), "Ten Steps in Scale Development and Reporting: A Guide for Researchers", Communication Methods and Measures, Vol. 12 No. 1, pp. 25-44.

Chae, B., Yang, C., Olson, D., and Sheu, C. (2014), "The impact of advanced analytics and data accuracy on operational performance: A contingent resource based theory (RBT) perspective", Decision Support Systems, Vol. 59 No. 1, pp. 119-126.

Chatterjee, S. (2020), "Dark side of online social games (OSG) using Facebook platform: effect of age, gender, and identity as moderators", Information Technology \& People, https://doi.org/10.1108/ITP-05-2020-0267.

Chatterjee, S., Kar, A.K., Dwivedi, Y.K. and Kizgin, H. (2019), "Prevention of cybercrimes in smart cities of India: from a citizen's perspective", Information Technology \& People, Vol. 32 No. 5, pp. 1153-1183. 
Chidlow, A., Ghauri, P., Yeniyurt, S., and Cavusgil, S. T. (2015), "Establishing rigor in mail survey procedures in international business research", Journal of World Business, Vol. 50 No. 1 , pp. 26-36.

Chin, W.W. (2010), How to write up and report PLS analyses. In Vinzi, V. E., Chin, W. W., Henseler, J., \& Wang, H. (Eds.), Handbook of partial least squares. pp. 655-690. Berlin, Heidelberg, Springer.

Columbus, L. (2014), " $84 \%$ of enterprises see big data analytics changing their industries' competitive landscapes in the next year", Forbes, https://www.forbes.com/sites/ louiscolumbus/2014/10/19/84-of-enterprises-see-big-data-analytics-changing-theirindustr ies-competitive-landscapes-in-the-next-year/\#66ed7a0c17de (Accessed on 16 December 2019).

Cosic, R., Shanks, G., and Maynard, S. (2015), "A business analytics capability framework", Australasian Journal of Information Systems, Vol. 19, pp. 5-19.

Cravens, D. W., Piercy, N. F., \& Baldauf, A. (2009), Management framework guiding strategic thinking in rapidly changing markets. Journal of Marketing Management, 25(1-2), 31-49.

Dahabiyeh, L., Najjar, M.S. and Agrawal, D. (2020), "The effect of risk levels on technology adoption decision: the case of online games", Information Technology \& People, Vol. 33 No. 5, pp. 1445-1464.

Delen, D., and Zolbanin, H. M. (2018), "The analytics paradigm in business research", Journal of Business Research, Vol. 90, pp. 186-195.

Dennehy, D. and Conboy, K. (2019), "Breaking the flow: a study of contradictions in information systems development (ISD)", Information Technology \& People, Vol. 33 No. 2, pp. 477 501.

Elbashir, M. Z., Collier, P. A., and Davern, M. J. (2008), "Measuring the effects of business intelligence systems: The relationship between business process and organizational performance", International Journal of Accounting Information Systems, Vol. 9 No. 3, pp. $135-153$.

Fornell, C., and Larcker, D.F. (1981), "Evaluating structural equation models with unobservable variables and measurement error", Journal of Marketing Research, Vol.18 No.1, pp. 3950.

Garrison, G., Wakefield, R.L., and Kim, S. (2015), "The effects of IT capabilities and delivery model on cloud computing success and firm performance for cloud supported processes and operations", International Journal of Management, Vol. 35 No. 4, pp. 377-393.

Gunasekaran, A., Papadopoulos, T., Dubey, R., Wamba, S. F., Childe, S. J., Hazen, B., and Akter, S. (2017), "Big data and predictive analytics for supply chain and organizational performance", Journal of Business Research, Vol. 70, pp. 308-317.

Hair, J. F., Ringle, C. M., and Sarstedt, M. (2011), "PLS-SEM: Indeed, a silver bullet", Journal of Marketing Theory and Practice, Vol. 19 No. 2, pp. 139-152.

Hair, J.F., Risher, J., Sarstedt, M., and Ringle, C.M. (2018), "When to use and how to report the results of PLS-SEM", European Business Review, Vol. 31 No.1, pp.2-24.

Henseler, J., Ringle, C.M., and Sarstedt, M. (2014), "A new criterion for assessing discriminant validity in variance-based structural equation modeling", Journal of the Academy of Marketing Science, Vol. 43 No. 1, pp. 115-135.

Henseler, J., Ringle, C.M., and Sinkovics, R.R. (2009), "The use of partial least squares path modeling in international marketing", Advances in International Marketing, Vol. 20 No.1, pp. 277-319. 
Hindle, G. A., and Vidgen, R. (2018), "Developing a business analytics methodology: A case study in the foodbank sector", European Journal of Operational Research, Vol. 268 No. 3, pp. 836-851.

Holsapple, C., Lee-Post, A., and Pakath, R. (2014), “A unified foundation for business analytics”, Decision Support Systems, Vol. 64, pp. 130-141.

Iyer, B., and Henderson, J.C. (2012), "Business value from clouds: learning from users", MIS Quarterly Executive, Vol. 11 No. 1, pp. 51-60.

Jayashankar, P., Johnston, W., Nilakanta, S. and Burres, R. (2019), "Co-creation of value-in-use through big data technology- a B2B agricultural perspective", Journal of Business \& Industrial Marketing Early Cite. https://doi.org/10.1108/JBIM-12-2018-0411.

Khan, G.F., Sarstedt, M., Shiau, W.-L., Hair, J.F., Ringle, C.M. and Fritze, M.P. (2019), "Methodological research on partial least squares structural equation modeling (PLSSEM): an analysis based on social network approaches", Internet Research, Vol. 29 No. 3, pp. 407-429.

Klatt, T., Schlaefke, M., and Moeller, K. (2011), "Integrating business analytics into strategic planning for better performance", Journal of Business Strategy, Vol. 32 No. 6, pp. 30-39.

Kock, N., and Lynn, G. (2012), "Lateral Collinearity and Misleading Results in Variance - Based SEM: An Illustration and Recommendations", Journal of Association of Information Systems, Vol. 13 No. 7, pp. 546-580.

Kor, Y.Y. and Mahoney, J.T. (2003), "Edith Penrose's (1959) Contributions to the Resource-based View of Strategic Management”, Journal of Management Studies, Vol. 41 No. 1, pp. 183191.

Larson, D., and Chang, V. (2016), "A review and future direction of agile, business intelligence, analytics and data science", International Journal of Information Management, Vol. 36 No.5, pp. 700-710.

London, T. (2016), The Base of the Pyramid Promise: Building Businesses with Impact and Scale, Stanford Business Books, Stanford, CA.

Loukis, E., Janssen, M., and Mintchevc, I. (2019), "Determinants of software-as-a-service benefits and impact on firm performance", Decision Support System, Vol. 117, pp. 38-47.

Lowry, P. B., and Gaskin, J. (2014), "Partial least squares (PLS) structural equation modeling (SEM) for building and testing behavioral causal theory: When to choose it and how to use it”, IEEE Transactions on Professional Communication, Vol. 57 No. 2, pp. 123-146.

Maldonado, M.U., Leusin, M.E., Bernardes, T.C.D.A. and Vaz, C.R. (2020), "Similarities and differences between business process management and lean management", Business Process Management Journal, In Press. https://doi.org/10.1108/BPMJ-09-2019-0368.

Malladi, S., and Krishnan, M. (2012), "Does software-as-a-service (SaaS) have a role in ITenabled innovation? - an empirical analysis", Proceedings of American Conference on Information Systems (AMCIS), Seattle, USA.

Mithas, S., Ramasubbu, N., and Sambamurthy, V. (2011), "How information management capability influences firm performance", MIS Quarterly, Vol. 35 No. 1, pp. 237-256.

Oesterreich, T.D. and Teuteberg, F. (2019), "The role of business analytics in the controllers and management accountants' competence profiles: An exploratory study on individual-level data", Journal of Accounting \& Organizational Change, Vol. 15 No. 2, pp. 330-356.

Pape, T. (2015), "Prioritizing data items for business analytics: Framework and application to human resources", European Journal of Operational Research, Vol. 252, pp. 687-698. 
Peppard, J., \& Ward, J. (2016), The strategic management of information systems: Building a digital strategy. John Wiley \& Sons Publication, USA.

Podsakoff, P.M., MacKenzie, S.B., Lee, J.Y., and Podsakoff, N.P. (2003), "Common method biases in behavioral research: A critical review of the literature and recommended remedies", Journal of Applied Psychology, Vol. 88 No. 5, pp. 879-903.

Porter, C. E., and Donthu, N. (2006), "Using the technology acceptance model to explain how attitudes determine internet usage: The role of perceived access barriers and demographics", Journal of Business Research, Vol. 59 No. 9, pp. 999-1007.

Priem, R. L. and Butler, J. (2001), "Is the Resource-Based 'View' a Useful Perspective for Strategic Management Research?", Academy of Management Review, Vol. 26 No. 1, pp. 20-40.

Ramanathan, R., Philpott, E., Duan, Y., and Cao, G. (2017), "Adoption of business analytics and impact on performance: A qualitative study in retail", Production Planning and Control, Vol. 28 No. 11/12, pp. 985-998.

Rodrigues, J., Ruivo, P., and Oliveira, T. (2014), "Software as a service value and firm performance - a literature review synthesis in small and medium enterprises", Procedia Technology, Vol.16, pp. 206-211.

Sarstedt, M., Ringle, C. M., and Hair, J. F. (2017), Partial least squares structural equation modeling. In C. Homburg, M. Klarmann, \& A. Vomberg (Eds.), Handbook of Market Research, pp. 1-40. Springer International Publishing.

Schniederjans, D.G., and Hales, D.N. (2016), "Cloud computing and its impact on economic and environmental performance: a transaction cost economics perspective", Decision Support System, Vol. 86, pp. 73-82.

Sedera, D. and Lokuge, S. (2019), "Does it get better over time? A longitudinal assessment of enterprise system user performance", Information Technology \& People, Vol. 33 No. 4, pp. 1098-1123.

Sha, X., Chen, J. and Teoh, S.Y. (2020), "The dynamics of IT-business strategic alignment: evidence from healthcare information systems implementation", Information Technology \& People, Vol. 33 No. 5, pp. 1465-1488.

Sharda, R., Delen, D., and Turban, E. (2016), Business intelligence, analytics, and data science: A managerial perspective (4th ed.). Saddle River, NJ, Pearson-Prentice Hall.

Sharma, R., Mithas, S., and Kankanhalli, A. (2014), "Transforming decision-making processes: A research agenda for understanding the impact of business analytics on organizations", European Journal of Information Systems, Vol. 23 No. 4, pp. 433-441.

Shehata, G.M. and Montash, M.A. (2019), "Driving the internet and e-business technologies to generate a competitive advantage in emerging markets: Evidence from Egypt", Information Technology \& People, Vol. 33 No. 2, pp. 389-423.

Siala, H., Kutsch, E. and Jagger, S. (2019), "Cultural influences moderating learners' adoption of serious 3D games for managerial learning", Information Technology \& People, Vol. 33 No. 2, pp. 424-455.

Sun, Z., Strang, K., and Firmin, S. (2017), "Business analytics-based enterprise information systems", The Journal of Computer Information Systems, Vol. 57 No. 2, pp. 169-178.

Tan, F. T. C., Guo, Z., Cahalane, M., and Cheng, D. (2016), "Developing business analytic capabilities for combating e-commerce identity fraud: A study of Trustev's digital verification solution", Information \& Management, Vol. 53 No. 7, pp. 878-891. 
Tang, Z. and Chen, L. (2020), "Exploring the drivers of brand fan page follower discontinuance intention: an adaptation of the Furneaux and Wade's framework", Information Technology \& People, Vol. 33 No. 5, pp. 1381-1401.

Troilo, M., Bouchet, A., Urban, T.L., and Sutton, W.A. (2016), "Perception, reality, and the adoption of business analytics: Evidence from North American professional sport organizations", Omega, Vol. 59, pp. 72-83.

Venters, W., and Whitley, E. (2012), "A critical review of cloud computing: researching desires and reality", Journal of Information Technology, Vol. 27 No. 3, pp. 179-197.

Vidgen, R., Shaw, S., and Grant, D. B. (2017), "Management challenges in creating value from business analytics", European Journal of Operational Research, Vol. 261 No. 2, pp. 626639.

Voorhees, C.M., Brady, M.K., Calantone, R., and Ramirez, E. (2016), "Discriminant validity testing in marketing: an analysis, causes for concern, and proposed remedies", Journal of the Academy of Marketing Science, Vol. 44, pp. 119-134.

Wamba, S. F., Gunasekaran, A., Akter, S., Ren, S. J. F., Dubey, R., and Childe, S. J. (2017), "Big data analytics and firm performance: Effects of dynamic capabilities", Journal of Business Research, Vol. 70, pp. 356-365.

Wang, N., Liang, H., Jia, Y., Ge, S., Xue, Y., and Wang, Z. (2016), “Cloud computing research in the IS discipline: a citation/co-citation analysis”, Decision Support System, Vol. 86, pp. $35-47$.

Willaby, H.W., Costa, D.S.J., Burns, B.D., MacCann, C. and Roberts, R.D. (2015), “Testing complex models with small sample sizes: A historical overview and empirical demonstration of what partial least squares (PLS) can offer differential psychology", Personality and Individual Differences, Vol. 84, pp. 73-78.

Wójcik, P. (2015), "Exploring links between dynamic capabilities perspective and resource-based view: A literature overview", International Journal of Management and Economics, Vol. 45, pp. 83-107.

Wu, P.-J. S., Straub, W. D., and Liang, T.-P. (2015), "How information technology governance mechanisms and strategic alignment influence organizational performance: Insights from a matched survey of business and IT managers", MIS Quarterly, Vol. 39 No. 2, pp. 497518.

Zameer, H., Wang, Y., Yasmeen, H. and Mubarak, S. (2020), "Green innovation as a mediator in the impact of business analytics and environmental orientation on green competitive advantage", Management Decision, https://doi.org/10.1108/MD-01-2020-0065. 